\title{
A chemical kinetic study of the reaction of hydroxyl
} with furans

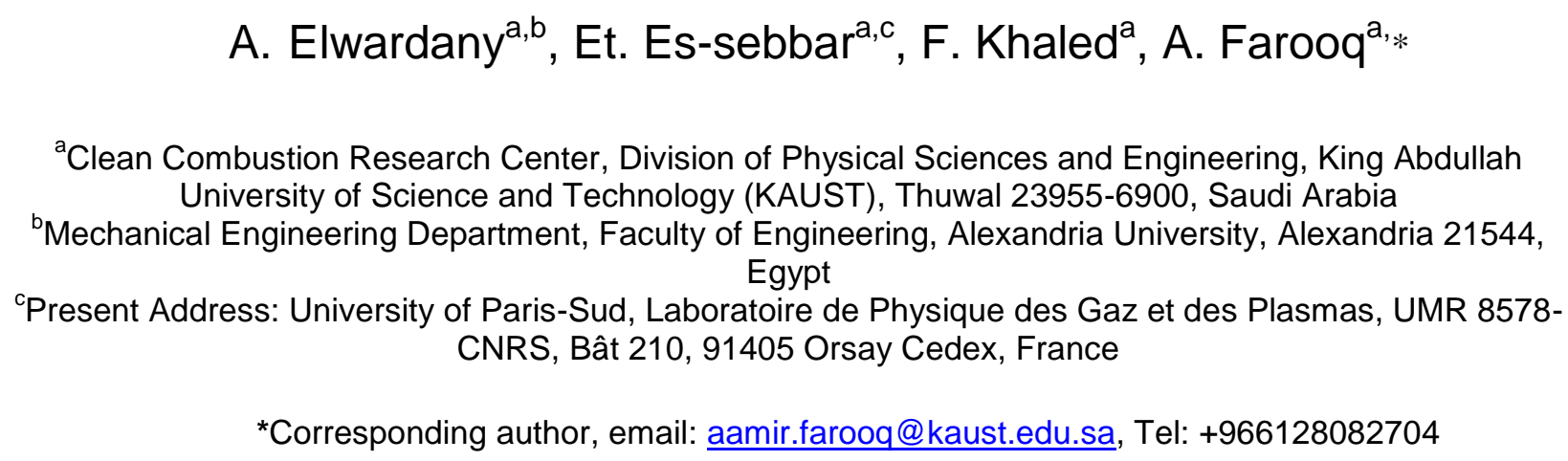




\section{Abstract}

14 Furans, a class of cyclic ethers, are potential renewable fuels and additives to 15 conventional fuels. High-temperature oxidation of furans is dominated by their reaction 16 with hydroxyl radical. In this work, rate coefficients for the reaction of hydroxyl $(\mathrm{OH})$ with 17 furan $\left(k_{1}\right)$, 2-methyl furan $\left(k_{2}\right)$ and 2,5-dimethyl furan $\left(k_{3}\right)$ were measured behind 18 reflected shock waves over a temperature range of $890-1388 \mathrm{~K}$ and pressures of $1-2$ 19 atm. Hydroxyl radicals were generated via the thermal decomposition of tert-butylhydroperoxide. The $\mathrm{OH}$ radicals were monitored using the well-characterized $R_{1}(5)$ 21 rotational line of the $A-X(0,0)$ band in the ultraviolet region near $306 \mathrm{~nm}$.

22 Measurements were carried out under pseudo-first-order conditions using two different 23 mixtures for each furan. The measured rate coefficients can be expressed in Arrhenius 24 form as:
$25 \quad k_{1}=783.39 \times T^{3} \exp (1866.7 / T)$
$\mathrm{cm}^{3} \mathrm{~mol}^{-1} \mathrm{~s}^{-1} \quad(924-1388 \mathrm{~K})$
$26 \quad k_{2}=8.85 \times 10^{13} \exp (-2285 / T)$
$\mathrm{cm}^{3} \mathrm{~mol}^{-1} \mathrm{~s}^{-1}$
$(890-1333 \mathrm{~K})$
$27 \quad k_{3}=1.03 \times 10^{14} \exp (-2128 / T)$
$\mathrm{cm}^{3} \mathrm{~mol}^{-1} \mathrm{~s}^{-1}$
$(915-1278 \mathrm{~K})$

28

29

30

31

32

33

34

35

This paper presents, to our knowledge, the first high-temperature measurements of the rate coefficients of the reactions of furan and its alkylated derivatives with the $\mathrm{OH}$ radical. These data will be critical in improving the predictive capability of chemical kinetic mechanisms of furans.

Keywords: Hydroxyl radical; furan; 2-methyl furan; 2,5-dimethyl furan; shock tube; laser absorption 


\section{Introduction}

Oxygenated fuels, including alcohols, esters, ethers, aldehydes and furans, are potential renewable fuels and additives to conventional fossil fuels. Furan, and its alkylated derivatives, have significant advantages over other oxygenated fuels as they can be produced from lignocellulose, which originates from crop, forest and municipal wastes [1-3]. Other oxygenated fuels, such as alcohols, are produced from crops and thus compete with the use of these crops as food. Additionally, the energy density of furans is higher than that of alcohols [2]. A comparison of different methodologies of obtaining oxygenated fuels from biomass can be ethers (furans) considered in this study.

Several engine studies have been carried out on furans as fuels or additives to traditional fuels to study engine performance and emission characteristics. A combustion and emissions study of 2,5 DMF in a single cylinder direct injection spark ignition (DISI) engine was carried out by Zhong et al. [6]. An extension to this work has been done by Daniel et al. [7] to compare performance and emissions of 2,5 DMF, ethanol and gasoline. It was shown that 2,5 DMF exhibited comparable combustion characteristics and emissions as gasoline, and in some cases, exceeded ethanol performance. Moreover, they investigated the hydrocarbon and carbonyl (aldehydes and ketones) emissions from a DISI engine for 2,5 DMF, alcohols (methanol, ethanol, n-butanol) and gasoline using gas chromatography, mass spectrometry and high-performance liquid chromatography. The results showed that 2,5 DMF produced the lowest

58 carbonyl emissions compared to other studied fuels [8]. Other engine studies carried out using

59 2,5 DMF [9] and 2 MF [10] showed that both fuels increased the octane number, and, hence, 60 raised the autoignition resistance. 
A number of fundamental kinetic studies have been carried out to understand the

chemical kinetic behavior of furans. Pyrolysis of furan, 2-methyl furan (2 MF) and 2,5-dimethyl furan (2,5 DMF) was studied by measuring the products from a heated flow reactor at temperatures ranging 1050 to $1270 \mathrm{~K}$ and low pressures ( $1 \mathrm{mTorr})$ [11]. Organ and Mackie [5] studied the pyrolysis of furan behind reflected shock waves over $1100-1700 \mathrm{~K}$ and pressure near 20 atm. High-temperature ignition delay times of furan were measured behind reflected shock waves at pressures ranging 1.2-10.4 atm for mixtures with equivalence ratios of $0.5,1.0$, and 2.0 and furan mole fractions of $0.25,0.5$ and $1 \%$ diluted in argon [12]. Tian et al. [13] measured species composition and temperature for a furan $/ \mathrm{O}_{2} / \mathrm{Ar}$ laminar flame using molecular beam mass spectrometry at low pressures (35 Torr) and equivalence ratios of 1.4, 1.8 and 2.2. Somers et al. [14] measured ignition delay times of 2-methyl furan behind reflected shock waves at atmospheric pressure, temperatures ranging $1200-1800 \mathrm{~K}$ and equivalence ratios of 0.5 , 1.0 and 2.0. They also measured laminar burning velocities for mixtures of 2 MF in air at equivalence ratios of $0.55-1.65$, initial temperatures of $298-398 \mathrm{~K}$ and atmospheric pressure. Wei et al. [15] measured ignition delay times of $2 \mathrm{MF} / \mathrm{O}_{2} / \mathrm{Ar}$ mixtures at temperatures of 1120 to $1700 \mathrm{~K}$, pressures of 1.25 to 10.65 bar and equivalence ratios of 0.25 to 2.0. For $2,5 \mathrm{DMF}$, Sirjean et al. [16] measured ignition delay times behind reflected shock waves at different equivalence ratios (0.5-1.5), temperatures of $1300-1831 \mathrm{~K}$ and pressures of 1 and 4 bar. Somers et al.[17] presented a comprehensive experimental study for the oxidation and pyrolysis of 2,5 DMF. They measured ignition delay times of $\mathrm{DMF} / \mathrm{O}_{2} /$ argon mixtures at atmospheric pressure, temperatures of $1350-1800 \mathrm{~K}$ and equivalence ratios of $0.5,1.0$ and 2.0. They also measured ignition delay times for stoichiometric fuel/air mixtures of 2,5 DMF at 20 and 80 bar and temperature ranging 820 to $1210 \mathrm{~K}$. Additionally, oxidation of 2,5 DMF was studied by Somers et al. [17] with a jet-stirred reactor (JSR) by measuring species concentrations. Somers et al. [17] also measured laminar burning velocities for 2,5 DMF/air mixtures at unburnt gas temperatures of 298 and $358 \mathrm{~K}$. Somers et al. [18] theoretically characterized the pyrolysis of 2 
MF using different quantum chemical methods. A recent study by Eldeeb and Akih-Kumgeh [19] compared ignition delay time measurements of furan, 2 MF and 2,5 DMF over 977-1570 K, pressures of 2, 5,10 and 12 atm and equivalence ratios of $0.5,1.0$ and 2.0. Their results showed that 2 MF is the most reactive fuel followed by furan and 2,5 DMF.

A series of three papers reported experimental data for flat flames of furan [20], 2 MF [21] and 2,5 DMF [22]. Experimental data and kinetic modeling was used to investigate the combustion chemistry of the three furans. The authors used a combination of high-resolution electron ionization molecular beam mass spectrometry (EI-MBMS) and gas chromatography (GC) to study two low-pressure (20 and 40 mbar) argon-diluted (50\%) laminar premixed flat flames at two equivalence ratios $(\phi=1.0$ and 1.7). Concentrations of reactants, intermediates and products were measured as a function of height above the burner surface. A detailed chemical kinetic model was developed to predict the flame structure of the three furans.

Another very important and fundamental kinetic target, less extensively studied, is the rate coefficient of the reaction of $\mathrm{OH}$ with furan, $2 \mathrm{MF}$ and 2,5 DMF.

$$
\begin{aligned}
& \text { Furan }+\mathrm{OH}=\text { Products } \\
& 2 \mathrm{MF}+\mathrm{OH}=\text { Products } \\
& 2,5 \mathrm{DMF}+\mathrm{OH}=\text { Products }
\end{aligned}
$$

For furan, $2 \mathrm{MF}$ and 2,5 DMF, the rate coefficients for their reactions with $\mathrm{OH}$ were measured at $300 \mathrm{~K}$ by [23-25] using a relative kinetic technique. Wine and Thompson [26] measured the rate coefficients for the reaction of $\mathrm{OH}$ with furan over a temperature range of $254-425 \mathrm{~K}$ using resonance fluorescence spectroscopy. Gomez Alvarez et al. [27] studied the OH-initiated photooxidation of furan, $2 \mathrm{MF}$ and $3 \mathrm{MF}$ at atmospheric conditions. The rate coefficients of R1-R3 have also been investigated in various theoretical studies. The rate coefficient of $\mathrm{R} 1$ and $\mathrm{R} 2$ were theoretically studied using multichannel RRKM-TST, direct-dynamics VTST [28] and by 
111 high level theoretical methods [29, 30]. In [29], it was shown that the addition channel dominates

112 at low temperatures. Zhang et al. [30, 31] calculated the potential energy surface and reaction

113 pathways for $\mathrm{R} 2$ and $\mathrm{OH}+3 \mathrm{MF}$ reaction. They considered three channels: hydrogen

114 abstraction, bimolecular nucleophilic substitution and $\mathrm{OH}$ addition/elimination. Their results

115 revealed that the addition-elimination channel is the dominant one at low to moderately high

116 temperatures. The same conclusion was drawn for room-temperature reaction of $\mathrm{OH}$ with

117 various aromatic hydrocarbons including benzene, toluene, xylene isomers and

118 trimethylbenzenes [32].

The focus of the current work is to fill the gap in the high-temperature rate

measurements of the reaction of hydroxyl radical with furan, 2 MF and 2,5 DMF. Hydroxyl

121 radicals are generated via thermal decomposition of tert-butyl-hydroperoxide. Rate coefficient

122 measurements are carried out behind reflected shock waves using narrow line-width absorption

123 of $\mathrm{OH}$ radical near $306.7 \mathrm{~nm}$.

\section{Experiments}

All experiments were carried out in the high-purity, honed and electro-polished, stainless

127 steel shock tube facility at King Abdullah University of Science and Technology (KAUST). The

128 shock tube has an inner diameter of $14.2 \mathrm{~cm}$, driven section is $9 \mathrm{~m}$ long while the driver section

129 length can be varied to a maximum of $9 \mathrm{~m}$. Five PCB (Model 113B26) piezo-electric pressure

130 transducers (PZT), spaced over the last 1.3 meters of the driven section, were used to

131 determine the incident shock velocity $( \pm 0.2 \%)$. Temperature $\left(T_{5}\right)$ and pressure $\left(P_{5}\right)$ behind

132 reflected shock waves are calculated using standard normal shock relations. Thermochemical

133 data are taken from the Sandia Thermodynamic Database [33] and recent cyclic either

134 mechanism [20-22]. Calculated temperature and pressure have uncertainties of $\pm 0.7 \%$ and \pm

$1351.0 \%$, respectively, primarily due to the uncertainty in the measured incident shock velocity. 
Chrystie et al. [34] measured the temperature behind reflected shock waves using quantum cascade laser absorption and showed that the calculated temperatures are within $2-3 \%$ of the measured temperatures. A turbo-molecular pump (Varian TV 551) was used to pump down the driven section of the shock tube for about 30 minutes between two successive experiments and an ultimate pressure of $2 \times 10^{-5}$ mbar was achieved without-gassing leak rate of $5 \times 10^{-6}$ $\mathrm{mbar} / \mathrm{min}$. Further details of the shock tube facility can be found elsewhere [34-36].

Test gas mixtures were prepared using research-grade argon (99.999\%), 70\% TBHP (tert-butyl-hydroperoxide) aqueous solution and furan ( $\geq 99 \%), 2$ MF (99\%) or 2,5 DMF (99\%). Argon was supplied by Abdullah Hashim Gases (AHG) and other chemicals were procured from Sigma Aldrich. TBHP is a well-known thermal precursor of $\mathrm{OH}$ radicals [37]. A comparison between TBHP and gaseous nitric acid as $\mathrm{OH}$ precursors can be found in [37, 38]. Repeated freeze-pump-thaw cycles were used to further purify the furans before preparing the gas mixtures. High-purity helium (99.99\%), supplied by AHG, was used as the driver gas.

Temporal $\mathrm{OH}$ radical concentration was measured behind reflected shock waves using the well-characterized $R_{1}(5)$ absorption line of the $\mathrm{OH} A-X(0,0)$ band near $306.69 \mathrm{~nm}$. A 532 $\mathrm{nm}(10 \mathrm{~W}, \mathrm{cw})$ green laser pumped a Rhodamine $\mathrm{B}$ dye-laser $(0.75 \mathrm{~g} / \mathrm{L}$ Rhodamine $\mathrm{B}$ in ethylene glycol) to generate visible red light near $613.4 \mathrm{~nm}(\sim 1 \mathrm{~W})$. The red light was frequency doubled to generate ultraviolet light ( $100 \mathrm{~mW}$ ) near $306.7 \mathrm{~nm}$. A common-mode-rejection scheme was used to minimize the noise to signal ratio (see Figure 1 in [35]). Hydroxyl radical mole fraction $\left(X_{O H}\right)$ was calculated using the Beer-Lambert law, $I / I_{0}=\exp \left(-k_{v} X_{O H} P_{5} L\right)$, where $I$ and $I_{0}$ are the transmitted and incident laser intensities, respectively, $k_{v}$ is the absorption coefficient calculated following the work of Herbon [39], $P_{5}$ is the total reflected shock pressure (atm) and $L$ is the optical path length $(14.2 \mathrm{~cm})$. The overall estimated uncertainty in the measured $\mathrm{OH}$ mole fraction is approximately $\pm 5 \%$, mainly due to the uncertainties in the 
160

161

162

163

164

165

166

167

168

169

170

171

172

173

174

175

176

177

178

179

180

181

182

183

184

reflected-shock temperature and absorption coefficient. All experimental data were recorded at 2.5 $\mathrm{MHz}$ sampling rate using a high-resolution (14 bit) data acquisition system.

\section{Results}

Hydroxyl radical profiles are simulated with a chemical kinetic mechanism and the target rate (fuel $+\mathrm{OH}$ ) is varied until a best fit is achieved with the measured $\mathrm{OH}$ mole fraction profile. Detailed kinetic mechanism developed by Kohse-Höinghaus et al. [20-22] for furan, 2 MF and 2,5 DMF is used as the base mechanism. A TBHP $((\mathrm{CH} 3) 3-\mathrm{CO}-\mathrm{OH})$ chemistry set, described in [40-43], is included in the base mechanism to simulate the formation of $\mathrm{OH}$. Following Benson and O'Neal [44], TBHP decomposes almost instantaneously to form the $\mathrm{OH}$ radical and a tertbutoxy radical, which in turn decomposes to form acetone and a methyl radical. Moreover, the $\mathrm{OH}$ radical can attack TBHP to produce water and other products [41-43]. The rate coefficients of the TBHP relevant reactions and thermodynamic properties of the newly introduced species are taken as described in Lam et al. [40]. All zero-dimensional simulations are performed using CHEMKIN-PRO [45] software package with constant volume and energy constraints (constant UV). Measurements are performed under pseudo-first-order conditions by having fuel (furan, 2 MF or 2,5 DMF) concentrations to be at least ten times larger than $\mathrm{OH}$ concentration. The rate coefficients for reactions of $\mathrm{R} 1$ - R3 are measured behind reflected shock waves over a temperature range of $890-1388 \mathrm{~K}$ and pressures ranging $1.05-1.95 \mathrm{~atm}$.

\subsection{Kinetics of furan $+\mathrm{OH}$}

A representative hydroxyl radical sensitivity analysis is shown in Fig. 2 for a mixture of 228 ppm furan with 11 ppm TBHP (and 30 ppm $\mathrm{H}_{2} \mathrm{O}$ ) diluted in argon. Reflected shock conditions are $1015 \mathrm{~K}$ and $1.56 \mathrm{~atm}$. The $\mathrm{OH}$ sensitivity is calculated as $S=\left(\partial X_{O H} / \partial k_{i}\right) \times\left(k_{i} / X_{O H}\right)$, where $\mathrm{X}_{\mathrm{OH}}$ is the $\mathrm{OH}$ mole fraction and $k_{i}$ is the rate coefficient of the $i^{\text {th }}$ reaction. 
Sensitivity analysis shown in Fig. 2 shows that the reaction of furan with $\mathrm{OH}$ (R1) is the dominant reaction over the entire time frame of the experiments $(\sim 200 \mu \mathrm{s})$. For low temperatures and at early times $(<10 \mu \mathrm{s})$, minor interference from the decomposition reaction of TBHP is seen. However, the influence of this interference on the $\mathrm{OH}$ radical decay and on the deduced reaction rate is negligible. At longer times (> $200 \mu \mathrm{s})$, secondary reactions, such as the following, start to show some interference.

$$
\begin{gathered}
\mathrm{CH}_{3}+\mathrm{OH} \leftarrow \mathrm{CH}_{2}+\mathrm{H}_{2} \mathrm{O} \\
\mathrm{CH}_{3}+\mathrm{CH}_{3}(+\mathrm{M}) \leftarrow \mathrm{C}_{2} \mathrm{H}_{6}(+\mathrm{M}) \\
\mathrm{CH}_{3} \mathrm{COCH}_{3}+\mathrm{OH} \leftarrow \rightarrow \mathrm{CH}_{3} \mathrm{COCH}_{2}+\mathrm{H}_{2} \mathrm{O} \\
\mathrm{CH}_{3} \mathrm{OH}(+\mathrm{M}) \leftarrow \rightarrow \mathrm{CH}_{3}+\mathrm{OH}(+\mathrm{M})
\end{gathered}
$$

The rate coefficient of reaction $\mathrm{R} 4$ was updated in the base mechanism with the measured values proposed by Pang et al. [46]. The rate coefficient of reaction R5 was updated as measured by Oehlschlaeger et al. [47], while the rate coefficient for reaction R6 was updated with the measured values from Lam et al. [40]. Finally, the rate coefficient of reaction R7 was updated with the values measured by Srinivasan et al. [48].

A representative measured $\mathrm{OH}$ mole fraction profile for a mixture of $228 \mathrm{ppm}$ furan/11 ppm TBHP/30 ppm water diluted in argon is shown in Fig. 3 at reflected shock temperature and pressure of at $1015 \mathrm{~K}$ and $1.56 \mathrm{~atm}$, respectively. The best-fit rate coefficient for $\mathrm{R} 1$ and perturbations of $\pm 20 \%$ in the inferred rate coefficient are also presented in Fig. 3. Time zero is determined by matching the peak of simulated $\mathrm{OH}$ profile with the measured $\mathrm{OH}$ peak. The experimental slow rise of $\mathrm{OH}$ radical before $\mathrm{t}=0$ (for temperatures $>1000 \mathrm{~K}$ ) is attributed to the relatively low bandwidth $(760 \mathrm{kHz})$ of the photo-detector. The detector bandwidth can be set as high as $10 \mathrm{GHz}$ but the signal-to-noise-ratio is lower at higher bandwidth. At lower temperatures $(<1000 \mathrm{~K})$, the experimental slow rise of $\mathrm{OH}$ disappears because the detector bandwidth is high enough to capture the rise of $\mathrm{OH}$ fairly well. Figure 3 shows a notch, Schlieren spike, in the measured trace close to the peak, which is caused by the shock-induced density gradient. Table 
2111 summarizes the rate coefficient measurements of reaction $\mathrm{R} 1$ over a temperature range of

$212924-1388 \mathrm{~K}$ and pressures of $1.17-1.95 \mathrm{~atm}$. Rate coefficient measurements were performed

213 using two separate mixtures (see Table 1 and Fig. 5) to check if the mixture composition

214 affected the measured rates. The measured rate coefficients are found to be independent of the

215 mixture composition or fuel concentration for the range of conditions studied here.

216 Detailed error analysis was performed to estimate the overall uncertainty in the measured rate

217 coefficients of reaction $\mathrm{R} 1$ at representative condition of $1015 \mathrm{~K}$ and $1.56 \mathrm{~atm}$. The individual

218 sources of errors considered in this study include the temperature $( \pm 1 \%)$, mixture composition

219 ( $\pm 5 \%), \mathrm{OH}$ absorption coefficient $( \pm 3 \%)$, wavemeter reading $\left( \pm 0.002 \mathrm{~cm}^{-1}\right)$, fitting the

220 experimental profiles $( \pm 5 \%)$, locating time zero $( \pm 1 \mu \mathrm{s})$, rate coefficient of $\mathrm{CH}_{3}+\mathrm{OH}=\mathrm{S}-\mathrm{CH}_{2}+$

$221 \mathrm{H}_{2} \mathrm{O}$ (uncertainty factor $=2$ ), rate coefficient of $\mathrm{CH}_{3}+\mathrm{CH}_{3}=\mathrm{C}_{2} \mathrm{H}_{6}( \pm 20 \%)$, rate coefficient of

$222 \mathrm{CH}_{3} \mathrm{COCH}_{3}+\mathrm{OH}=\mathrm{CH}_{3} \mathrm{COCH}_{2}+\mathrm{H}_{2} \mathrm{O}\left(+17 \%\right.$, -28\%) and the rate coefficient of $\mathrm{CH}_{3} \mathrm{OH}=\mathrm{CH}_{3}+$

$223 \mathrm{OH}$ (uncertainty factor $=2$ ). The contribution of each of these error sources on the determination

224 of $k_{1}$ is calculated separately and presented in Fig. 4. The overall uncertainty is calculated using

225 the root-sum-squared method and is found to be $+15 \% /-20 \%$ for $k_{1}$ at $1015 \mathrm{~K}$.

226 The measured rate coefficients for reaction $\mathrm{R} 1$ (furan $+\mathrm{OH}$ ) are plotted in Fig. 5 over a

227 temperature range of $924-1388 \mathrm{~K}$. The values adopted in the kinetic mechanism of Liu et al.

228 [20] are also shown and agree quite well with the current measurements. The measured rate

229 coefficients can be expressed in a modified Arrhenius form as:

$230 \quad k_{1}=783.39 \times T^{3} \exp (1866.7 / T) \quad \mathrm{cm}^{3} \mathrm{~mol}^{-1} \mathrm{~s}^{-1}$

231 The measurements, and adopted values of Liu et al. [20], exhibit a slight non-Arrhenius

232 curvature over the temperature range of this study. Also, the activation energy of the reaction is 233 relatively small over this temperature range. It can be argued that the reaction of hydroxyl with 234 furan predominantly follows addition-elimination pathway than direct $\mathrm{H}$-abstraction. 


\subsection{Kinetics of 2-methyl furan $+\mathrm{OH}$}

237 The overall rate coefficients of the reaction of 2-methyl furan (2 MF) with $\mathrm{OH}$ were measured 238 behind reflected shock waves over a temperature range of $890-1333 \mathrm{~K}$ and pressures near 1 $239-1.5 \mathrm{~atm}$. Similar to the furan $+\mathrm{OH}$ case, two test mixtures were used: $258 \mathrm{ppm} 2 \mathrm{MF} / 12 \mathrm{ppm}$ 240 TBHP/32 ppm $\mathrm{H}_{2} \mathrm{O}$ diluted in argon and 153 ppm 2 MF/13 ppm TBHP/34 ppm $\mathrm{H}_{2} \mathrm{O}$ diluted in 241 argon. The $\mathrm{OH}$ sensitivity analysis for the second mixture is shown in Fig. 6 at reflected shock 242 conditions of $1150 \mathrm{~K}$ and $1.43 \mathrm{~atm}$. The dominant reaction is $\mathrm{R} 2(2 \mathrm{MF}+\mathrm{OH} \rightarrow$ Products) while 243 the primary interfering reactions are $\mathrm{R} 4-\mathrm{R} 7$. The rate coefficients for these reactions were 244 updated in the base mechanism, as discussed earlier.

245 Figure 7 shows a representative measured $\mathrm{OH}$ temporal profile at $1150 \mathrm{~K}$ and 1.43 atm. The 246 best-fit simulated $\mathrm{OH}$ profile and perturbations of $\pm 20 \%$ in the inferred rate coefficient are also 247 shown in Fig. 7. A more noticeable Schlieren spike is seen in Fig. 7 compared to Fig. 3. The 248 higher temperature case shown in Fig. 7 causes relatively large density change which results in 249 a larger Schlieren spike. Rate coefficients of reaction R2, measured over $890-1327 \mathrm{~K}$, are 250 presented in Table 2 and plotted in Fig. 8. Two different mixture compositions were employed to 251 confirm the independency of the rate coefficients on secondary chemistry effects. Rate 252 coefficient values adopted in the kinetic mechanisms of Tran et al. [21] and Sirjean et al. [16] 253 are also shown in Fig. 8. Both mechanisms have employed identical Arrhenius expression for $254 k_{2}$. The predicted rate coefficients are approximately 50\% slower than the current 255 measurements for temperatures less than $1150 \mathrm{~K}$, while the predictions agree well with current 256 measurements for higher temperatures $(T \geq 1300 \mathrm{~K})$. The values of the measured rate 257 coefficient can be expressed in Arrhenius form as:

$258 \quad k_{2}=8.85 \times 10^{13} \exp (-2285 / T) \mathrm{cm}^{3} \mathrm{~mol}^{-1} \mathrm{~s}^{-1}$ 
Detailed error analysis was performed for $\mathrm{k}_{2}$ measurements in a manner analogous to that described for $\mathrm{k}_{1}$. The overall uncertainty in the measured rate coefficient of reaction $\mathrm{R} 2$ comes out to be $+17 \% /-21 \%$ at $1150 \mathrm{~K}$.

\subsection{Kinetics of 2,5-dimethyl furan $+\mathrm{OH}$}

Following the same procedure of measuring rate coefficients of reactions $\mathrm{R} 1$ and $\mathrm{R} 2$, the overall rate coefficients of the reaction of 2,5-dimethyl furan (2,5 DMF) with $\mathrm{OH}$ were measured behind reflected shock waves for a temperature range of $915-1278 \mathrm{~K}$ and pressures near $1.2-1.7$ atm. To investigate any potential interference from secondary reactions, two test mixtures were used: 250 ppm 2,5 DMF/16 ppm TBHP/38 ppm $\mathrm{H}_{2} \mathrm{O}$ in argon and 191 ppm 2,5 DMF/14 ppm TBHP/34 ppm $\mathrm{H}_{2} \mathrm{O}$ in argon. Figure 9 shows representative sensitivity analysis for the second mixture at reflected shock conditions of $1251 \mathrm{~K}$ and $1.28 \mathrm{~atm}$. It can be seen that the target reaction $\mathrm{R} 3$ is dominant for the first $70 \mu$ s and then the sensitivity to $\mathrm{R} 3$ decreases with an increase in interference from $\mathrm{CH}_{3}+\mathrm{OH}(\mathrm{R} 4)$. Therefore, we have only used the first $50-70 \mu \mathrm{s}$ of the measured $\mathrm{OH}$ profiles to deduce $k_{3}$.

A representative measured $\mathrm{OH}$ time-history profile is shown in Fig. 10 at $1251 \mathrm{~K}$ and $1.28 \mathrm{~atm}$. The TBHP chemistry set is added to the chemical kinetic mechanism of Togbé et al. [22] to simulate the $\mathrm{OH}$ profiles. The best-fit simulated $\mathrm{OH}$ profile and perturbations of $\pm 20 \%$ in the inferred rate coefficient are shown in Fig. 10. Rate coefficients of reaction R3, measured over $915-1278 \mathrm{~K}$, are presented in Table 3 and plotted in Fig. 11. Rate coefficient values adopted in mechanisms of Togbé et al. [22], Sirjean et al. [16] and Somers et al. [17] are also shown in Fig. 11. The values of $k_{3}$ from Togbé et al. [22] and Sirjean et al. [16] are equal and approximately two times larger than the current measurements. However, the activation energy predicted by these models is quite similar to the activation energy of the measurements. Predicted values of $k_{3}$ by Somers et al. [17] show larger curvature and are even higher than the other two 
284 mechanisms. The values of the measured rate coefficient can be expressed in the Arrhenius 285 form as:

$286 k_{3}=1.03 \times 10^{14} \exp (-2128 / T) \mathrm{cm}^{3} \mathrm{~mol}^{-1} \mathrm{~s}^{-1}$.

287 Similar to the methodology used for $\mathrm{k}_{1}$, detailed error analysis was performed to estimate the 288 uncertainty in $\mathrm{k}_{3}$ and the uncertainty is found to be $+17 \% /-22 \%$ at $1251 \mathrm{~K}$.

289

290 The presence of the methyl group in the ring side affects the rate coefficients of the reaction of 291 hydroxyl with alkylated derivatives of furan, as can be seen in Fig. 12. The rate coefficients of 292 the reaction of 2,5 DMF with $\mathrm{OH}$ are approximately two times higher than those of 2 MF with $293 \mathrm{OH}$. This can be attributed to the fact that 2,5 DMF has two methyl groups while 2 MF has only 294 one. This variation of the measured total rate coefficients with number of methyl groups and the 295 Arrhenius nature of the rate coefficients suggests that, in our $\mathrm{T}$ range, $\mathrm{H}$-abstraction from the 296 methyl groups is comparable to or faster than competing pathways via addition of $\mathrm{OH}$ to the 297 furan ring. A direct measurement of the product branching ratio would be very helpful.

298 Our measured high-temperature rate coefficients are compared with low-temperature $(T<500$ 299 K) literature data in Figure S1 (Supplementary Material). The low-temperature data for all three 300 furans are higher than the corresponding measurements at high temperatures. This indicates 301 that $\mathrm{OH}$-addition pathways dominate for these furans at low temperatures. 


\section{Conclusions}

304 The overall rate coefficients for the reaction of $\mathrm{OH}$ radical with furan $\left(k_{1}\right), 2$-methyl furan $\left(k_{2}\right)$ 305 and 2,5-dimethyl furan $\left(k_{3}\right)$ are reported over a temperature range of $890-1388 \mathrm{~K}$ and 306 pressures near $1-2$ atm. The rate coefficients of 2,5 DMF $+\mathrm{OH}$ reaction are the largest 307 followed by $2 \mathrm{MF}+\mathrm{OH}$. The rate coefficients of furan $+\mathrm{OH}$ are smallest and show slight 308 curvature over the measured temperature range. Our high-temperature measurements are 309 smaller compared to the literature rate coefficient data at temperatures near $300 \mathrm{~K}$. This 310 indicates that $\mathrm{OH}$-addition pathways dominate for these cyclic ethers at low temperatures. The 311 reported measurements represent, to our knowledge, the first high-temperature rate coefficient 312 data for these cyclic ethers. Direct measurements of product branching ratios will be useful in 313 determining the branching of direct abstraction and addition pathways at intermediate to high 314 temperatures.

315

316 Acknowledgement

317 Research reported in this paper is funded by King Abdullah University of Science and 318 Technology (KAUST). 
Table 1. Rate coefficient data for furan $+\mathrm{OH}$ reaction.

\begin{tabular}{ccc}
$\mathrm{T}_{5}[\mathrm{~K}]$ & $\mathrm{P}_{5}[\mathrm{~atm}]$ & $k_{1}\left[\mathrm{~cm}^{3} \mathrm{~mol}^{-1} \mathrm{~s}^{-1}\right]$ \\
\hline $228 \mathrm{ppm}$ furan with $11 \mathrm{ppm} \mathrm{TBHP} / 30 \mathrm{ppm} \mathrm{H}_{2} \mathrm{O}$ in $\mathrm{Ar}$ \\
924 & 1.43 & $5.15 \mathrm{E}+12$ \\
991 & 1.37 & $5.19 \mathrm{E}+12$ \\
1000 & 1.56 & $5.25 \mathrm{E}+12$ \\
1015 & 1.56 & $5.22 \mathrm{E}+12$ \\
1046 & 1.51 & $5.35 \mathrm{E}+12$ \\
1135 & 1.38 & $5.67 \mathrm{E}+12$ \\
1176 & 1.95 & $5.76 \mathrm{E}+12$ \\
1188 & 1.77 & $5.98 \mathrm{E}+12$ \\
1197 & 1.57 & $5.95 \mathrm{E}+12$ \\
1224 & 1.43 & $6.24 \mathrm{E}+12$ \\
$167 \mathrm{ppm}$ furan with $13 \mathrm{ppm} \mathrm{TBHP} / 36 \mathrm{ppm} \mathrm{H}_{2} \mathrm{O}$ in $\mathrm{Ar}$ \\
1170 & 1.31 & $6.11 \mathrm{E}+12$ \\
1250 & 1.4 & $6.67 \mathrm{E}+12$ \\
1270 & 1.25 & $7.14 \mathrm{E}+12$ \\
1272 & 1.25 & $6.76 \mathrm{E}+12$ \\
1286 & 1.41 & $7.09 \mathrm{E}+12$ \\
1286 & 1.17 & $7.22 \mathrm{E}+12$ \\
1305 & 1.22 & $7.65 \mathrm{E}+12$ \\
1380 & 1.38 & $8.59 \mathrm{E}+12$ \\
1388 & 1.39 & $8.15 \mathrm{E}+12$ \\
& &
\end{tabular}

322 
Table 2. Rate coefficient data for $2 \mathrm{MF}+\mathrm{OH}$ reaction.

\begin{tabular}{ccc}
\hline $\mathrm{T}_{5}[\mathrm{~K}]$ & $\mathrm{P}_{5}[$ atm] & $\mathrm{k}_{2}\left[\mathrm{~cm}^{3} \mathrm{~mol}^{-1} \mathrm{~s}^{-1}\right]$ \\
$258 \mathrm{ppm}$ 2MF with 12 ppm TBHP / 32 ppm H${ }_{2} \mathrm{O}$ in $\mathrm{Ar}$ \\
890 & 1.56 & $6.26 \mathrm{E}+12$ \\
948 & 1.51 & $8.06 \mathrm{E}+12$ \\
972 & 1.44 & $9.07 \mathrm{E}+12$ \\
998 & 1.39 & $9.16 \mathrm{E}+12$ \\
1030 & 1.33 & $9.60 \mathrm{E}+12$ \\
1067 & 1.3 & $1.02 \mathrm{E}+13$ \\
$153 \mathrm{ppm} 2 \mathrm{MF}$ with $13 \mathrm{ppm} \mathrm{TBHP} \mathrm{/} \mathrm{34} \mathrm{ppm} \mathrm{H}_{2} \mathrm{O}$ in $\mathrm{Ar}$ \\
1106 & 1.39 & $1.17 \mathrm{E}+13$ \\
1150 & 1.43 & $1.19 \mathrm{E}+13$ \\
1166 & 1.38 & $1.22 \mathrm{E}+13$ \\
1181 & 1.36 & $1.29 \mathrm{E}+13$ \\
1189 & 1.34 & $1.34 \mathrm{E}+13$ \\
1250 & 1.38 & $1.38 \mathrm{E}+13$ \\
1280 & 1.39 & $1.48 \mathrm{E}+13$ \\
1301 & 1.15 & $1.53 \mathrm{E}+13$ \\
1317 & 1.05 & $1.53 \mathrm{E}+13$ \\
1327 & 1.17 & $1.58 \mathrm{E}+13$ \\
\hline
\end{tabular}

332

333

334

335

336

337

338

339

340

341

342

343

344 
Table 3. Rate rate coefficient data for 2,5 DMF $+\mathrm{OH}$ reaction.

\begin{tabular}{|c|c|c|}
\hline $\mathrm{T}_{5}[\mathrm{~K}]$ & $\mathrm{P}_{5}[\mathrm{~atm}]$ & $\mathrm{k}_{3}\left[\mathrm{~cm}^{3} \mathrm{~mol}^{-1} \mathrm{~s}^{-1}\right]$ \\
\hline \multicolumn{3}{|c|}{250 ppm 2,5 DMF with 16 ppm TBHP / 38 ppm $\mathrm{H}_{2} \mathrm{O}$ in $\mathrm{Ar}$} \\
\hline 915 & 1.56 & $9.55 \mathrm{E}+12$ \\
\hline 930 & 1.74 & $1.06 \mathrm{E}+13$ \\
\hline 1000 & 1.45 & $1.28 \mathrm{E}+13$ \\
\hline 1064 & 1.44 & $1.33 \mathrm{E}+13$ \\
\hline 1078 & 1.32 & $1.36 \mathrm{E}+13$ \\
\hline 1103 & 1.66 & $1.50 \mathrm{E}+13$ \\
\hline \multicolumn{3}{|c|}{191 ppm 2,5 DMF with 13 ppm TBHP / 34 ppm $\mathrm{H}_{2} \mathrm{O}$ in $\mathrm{Ar}$} \\
\hline 1134 & 1.35 & $1.57 \mathrm{E}+13$ \\
\hline 1204 & 1.38 & $1.75 E+13$ \\
\hline 1223 & 1.23 & $1.79 \mathrm{E}+13$ \\
\hline 1246 & 1.35 & $1.85 E+13$ \\
\hline 1246 & 1.19 & $2.00 \mathrm{E}+13$ \\
\hline 1251 & 1.28 & $1.83 E+13$ \\
\hline 1278 & 1.33 & $1.87 \mathrm{E}+13$ \\
\hline
\end{tabular}

346

347

348

349

350

351

352

353

354

355

356

357

358

359

360

361 
362 FIGURES

363

364
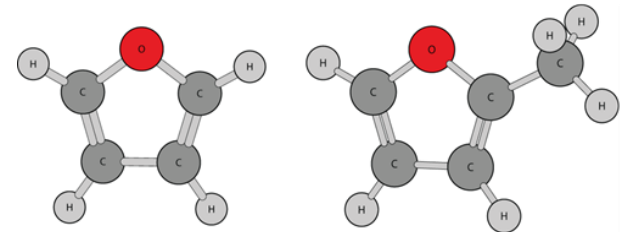

Furan

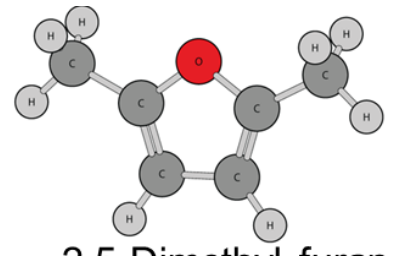

2,5 Dimethyl furan

365 Figure 1. Chemical structures of furan, 2-methyl furan (2 MF) and 2,5-dimethyl furan 366 (2,5 DMF). 


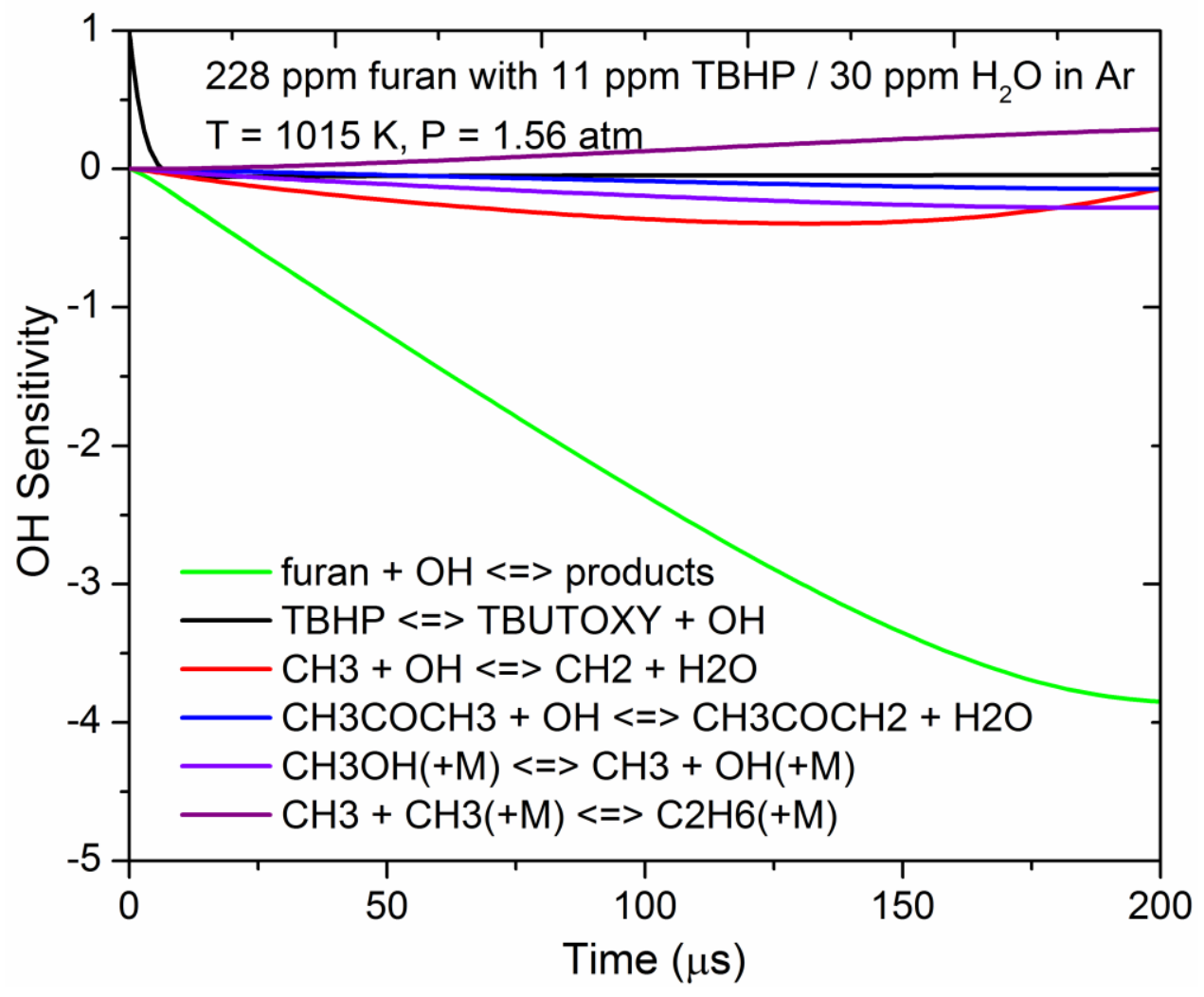

369 Figure 2. Hydroxyl radical sensitivity for the rate coefficient measurement of R1 (furan $+\mathrm{OH}$ ). 


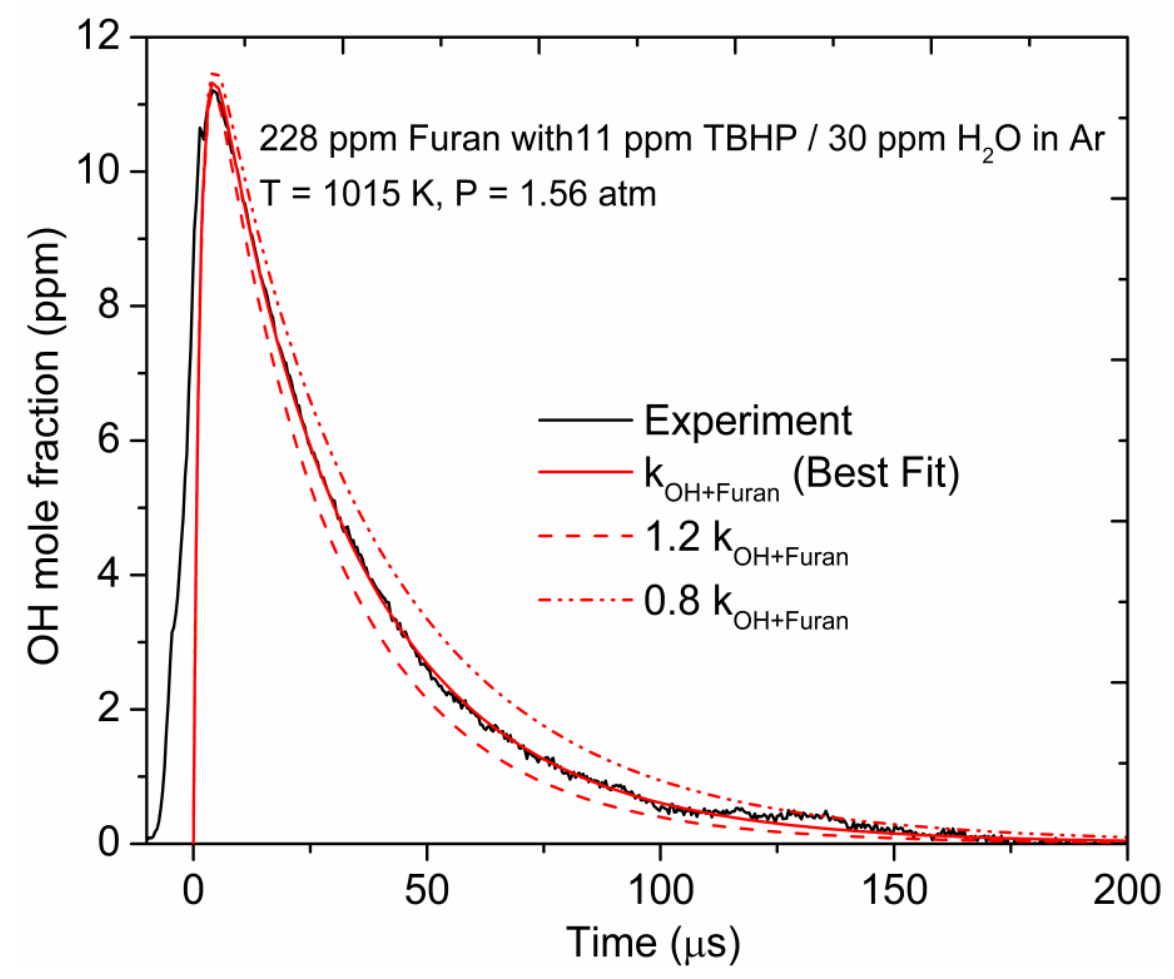

372 Figure 3. A representative measured $\mathrm{OH}$ temporal profile for the rate coefficient of furan $+\mathrm{OH}$. 373 Best-fit simulated rate coefficient and perturbations of $\pm 20 \%$ are also shown. Simulations are 374 performed using the Liu et al.[20] kinetic mechanism.

375

376 


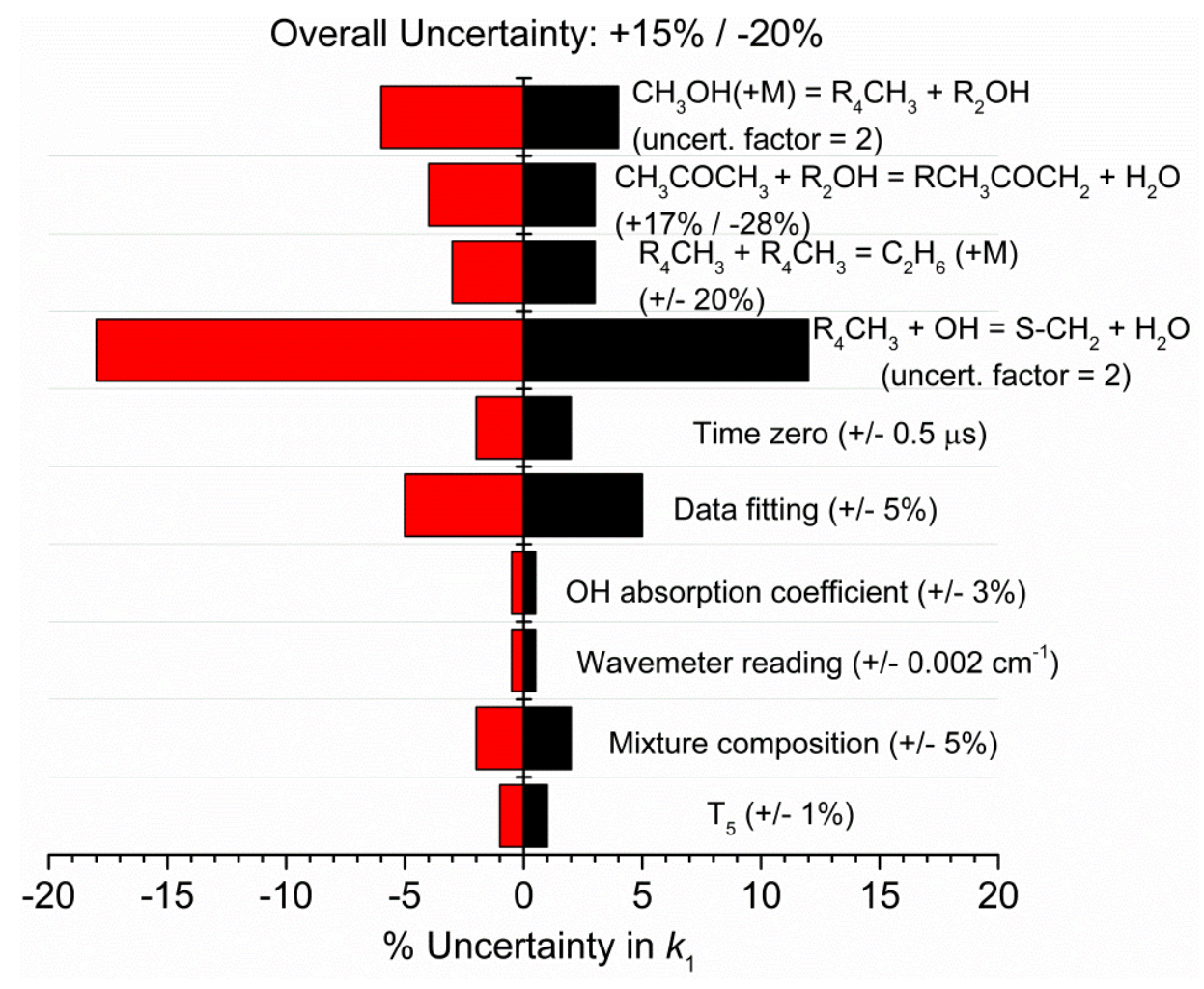

377

378

379

380

381
Figure 4. Uncertainty analysis for the rate coefficient of furan $+\mathrm{OH}$ reaction at the conditions of Fig. 3. 


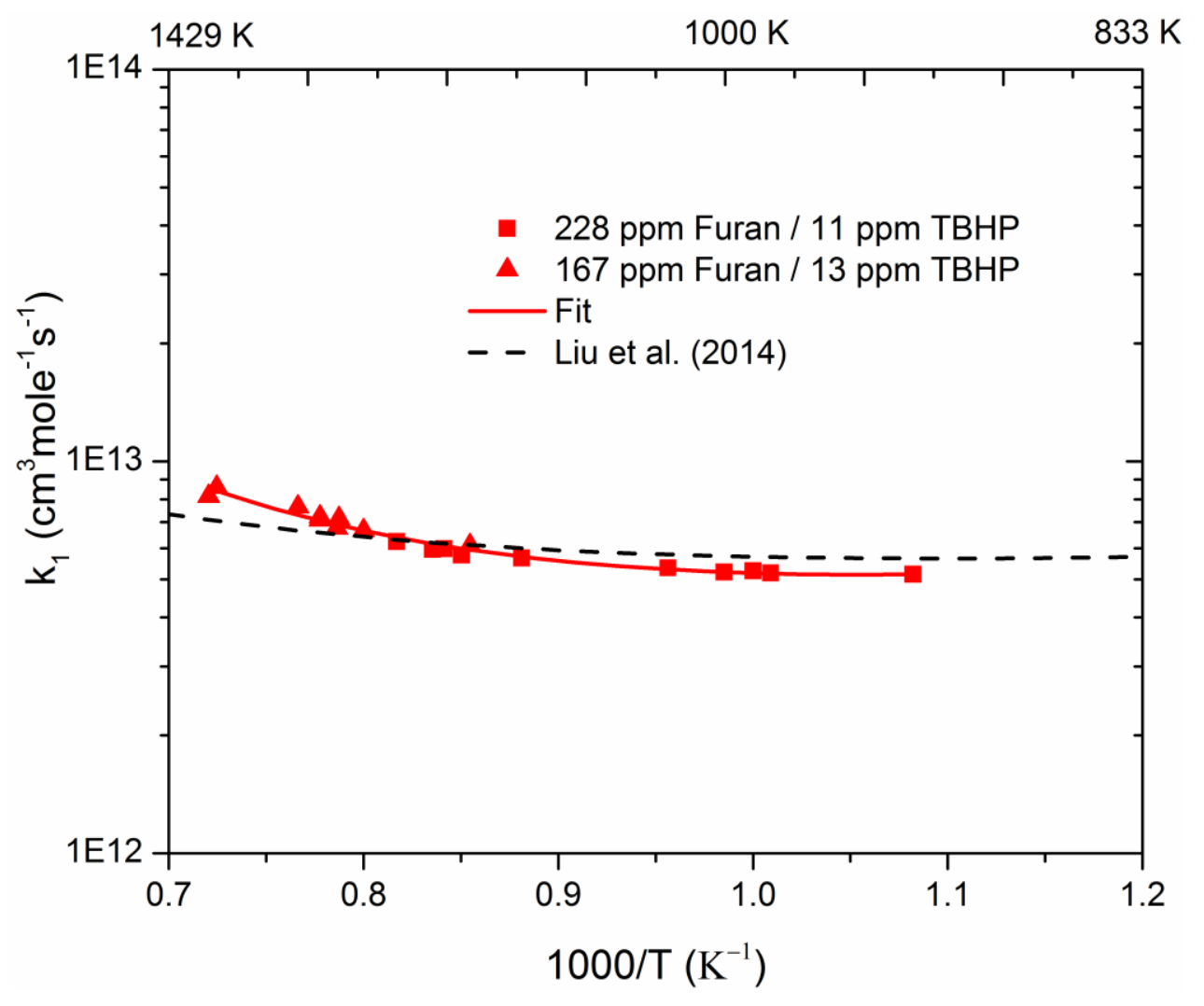




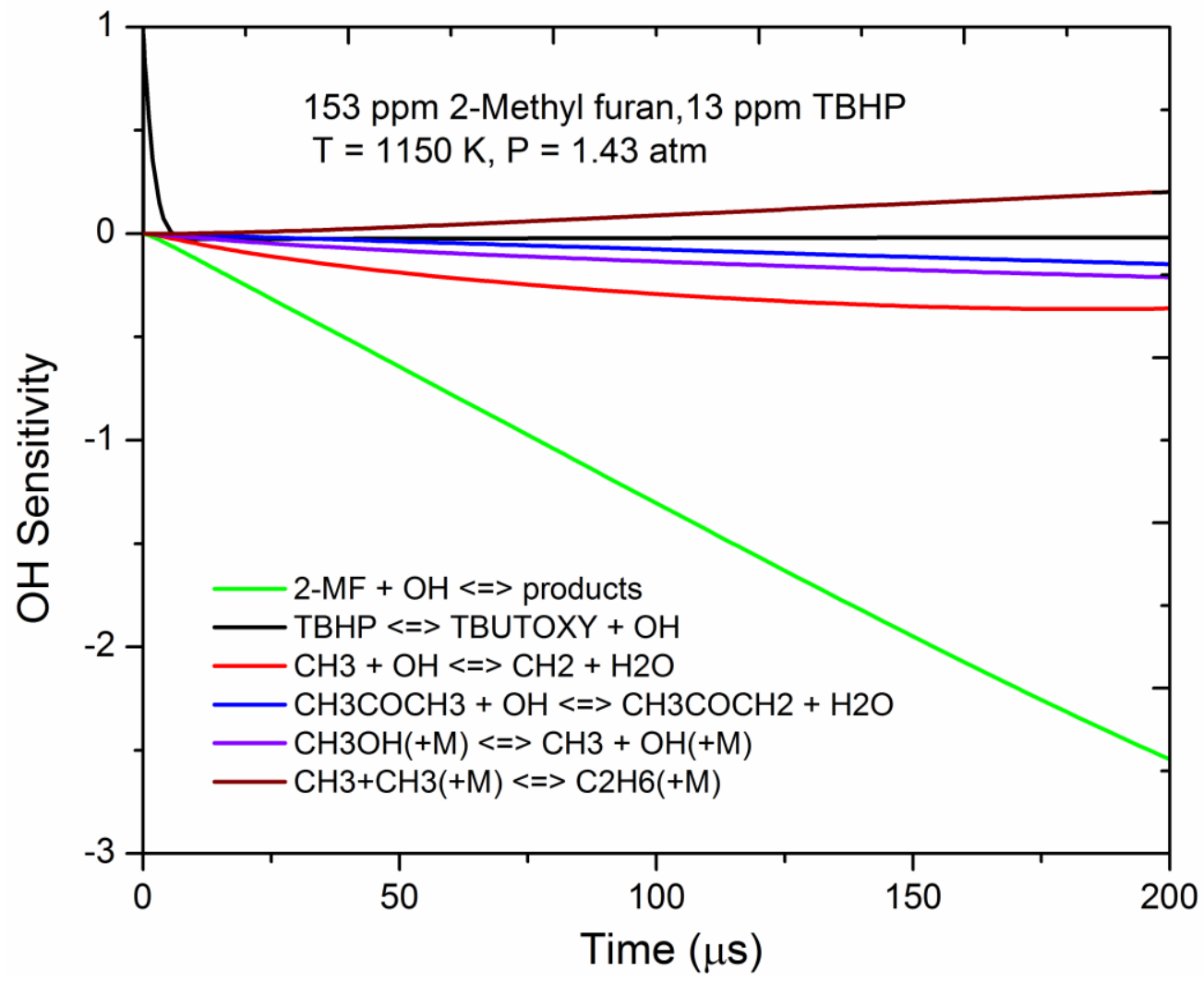

387

388

389

390

391 


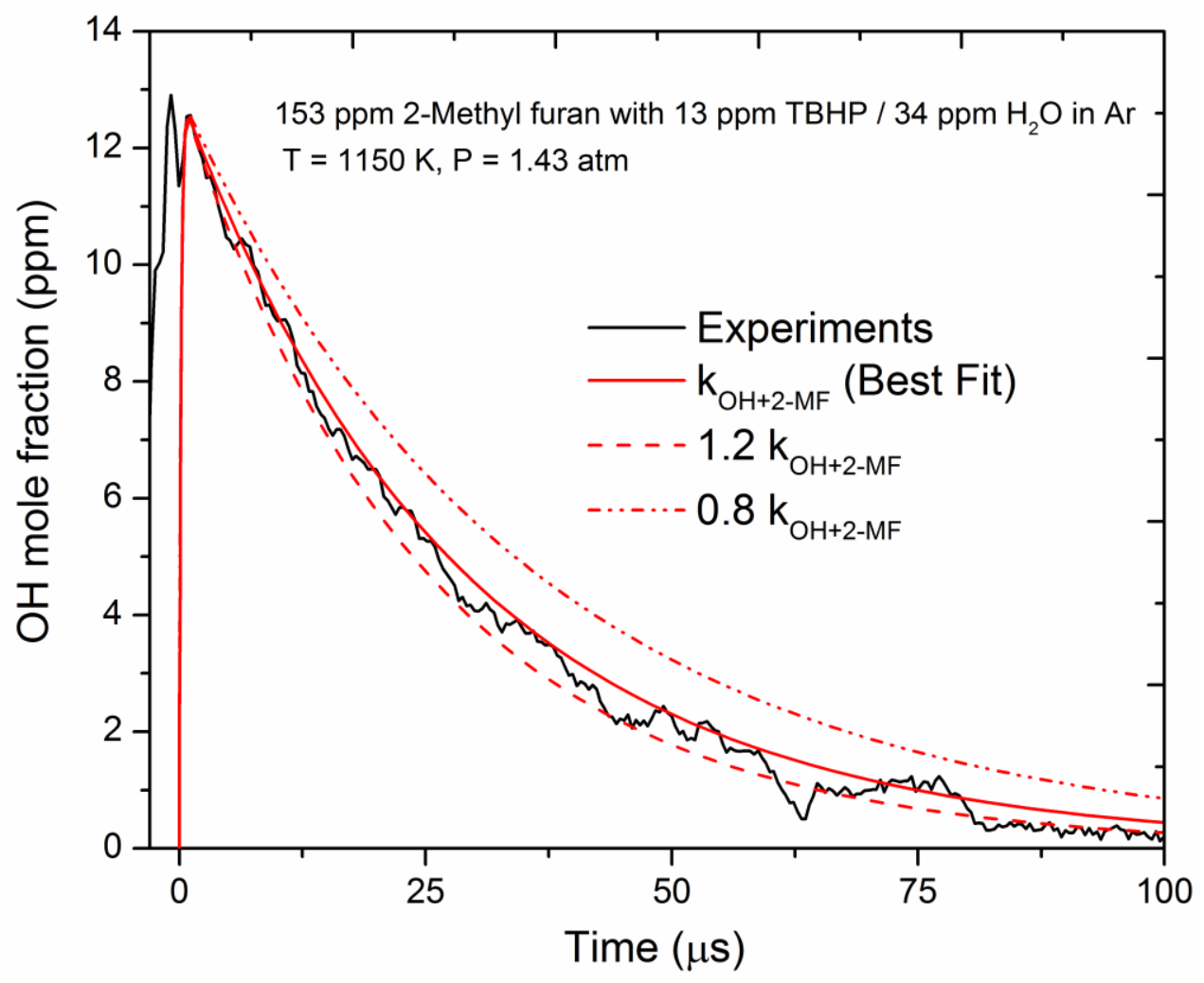

393 Figure 7. A representative measured $\mathrm{OH}$ temporal profile for measurements of the rate 394 coefficient of $2-\mathrm{MF}+\mathrm{OH}$. Best-fit simulated rate coefficient and perturbations of $\pm 20 \%$ are also 395 shown. Simulations are performed using the Tran et al.[21] mechanism. 


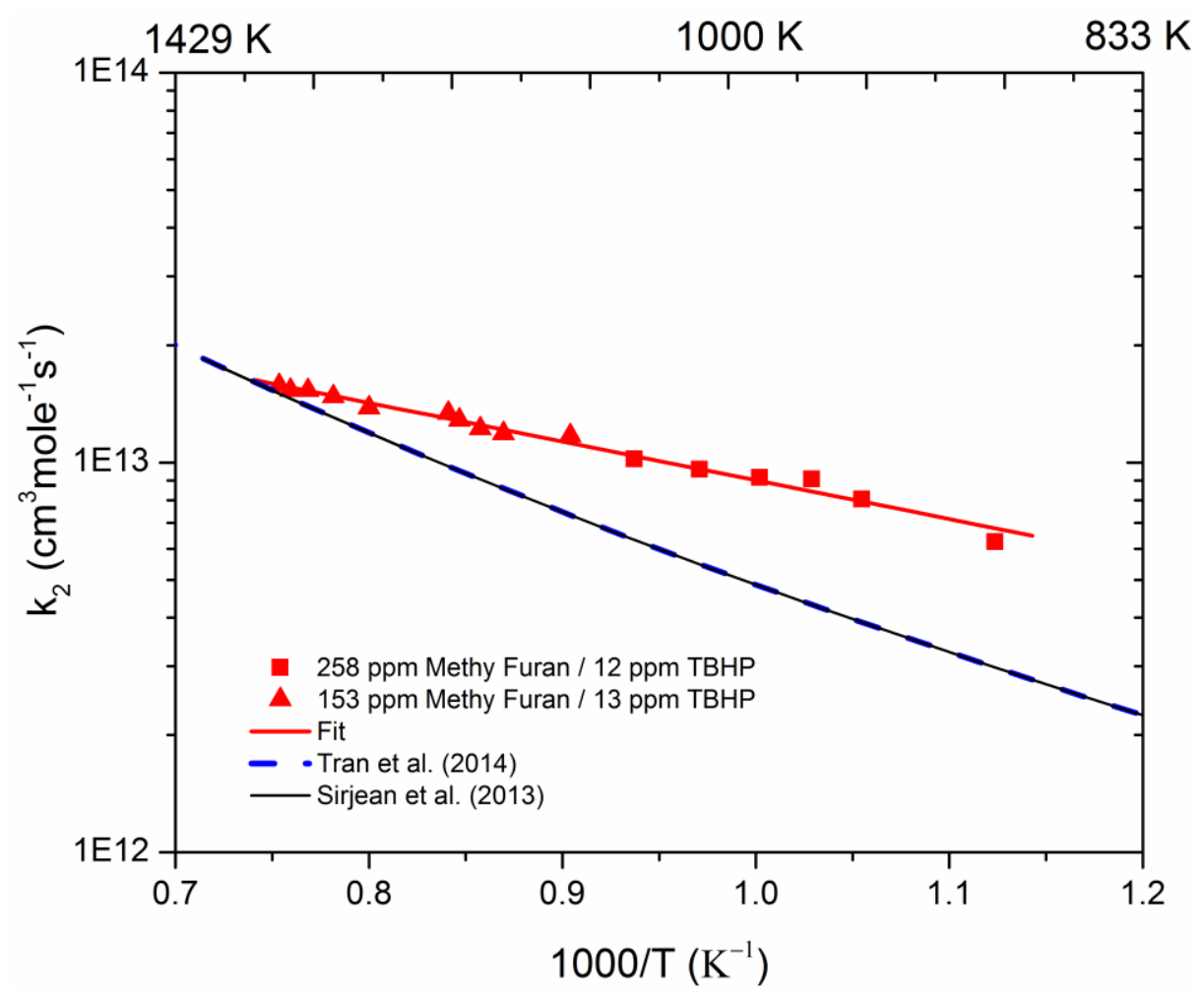

398

399

400

401

402

403

404 


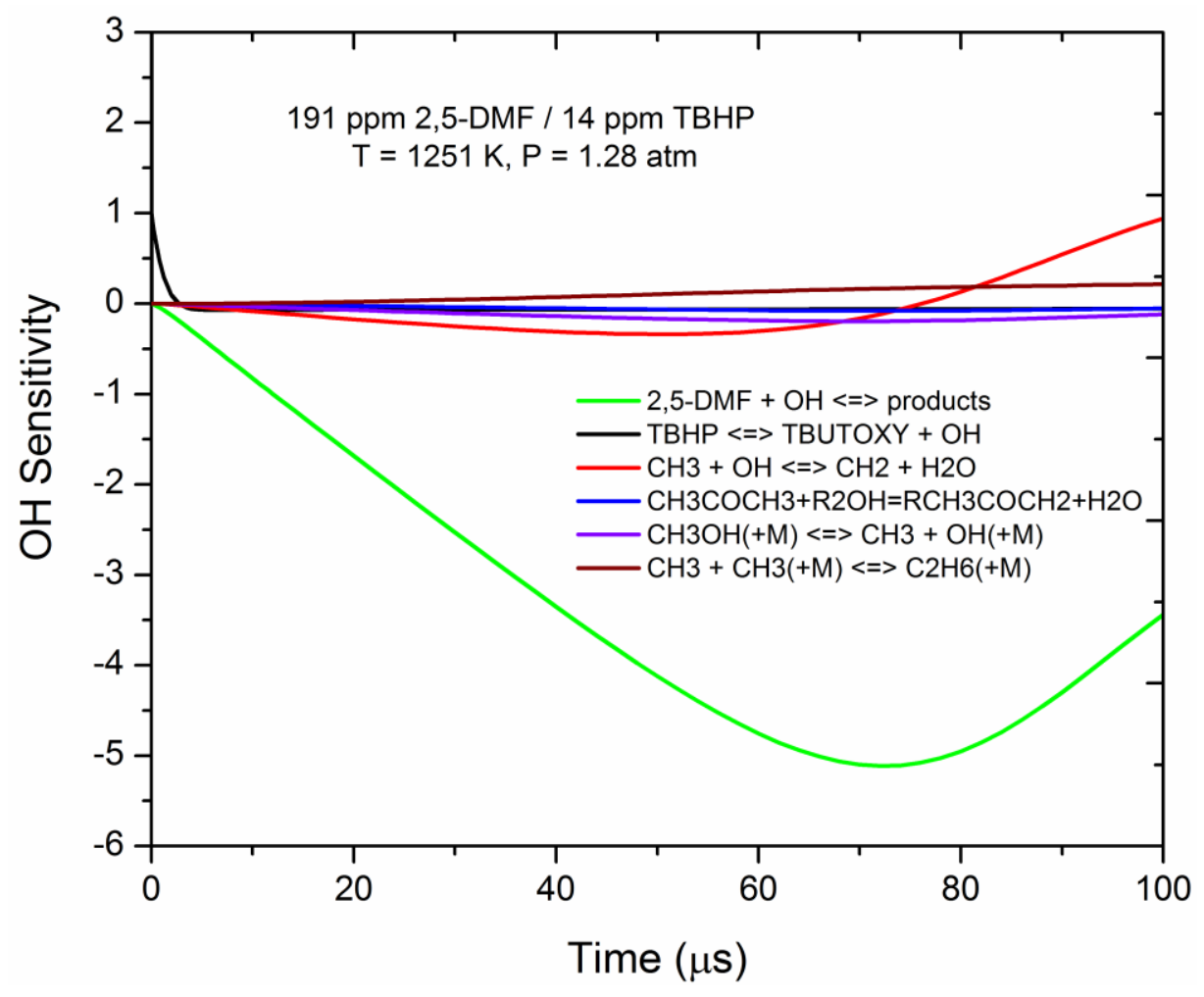

405

Figure 9. Hydroxyl sensitivity for the rate constant measurement of R3 at $1251 \mathrm{~K}$ and 1.28 atm.

407 


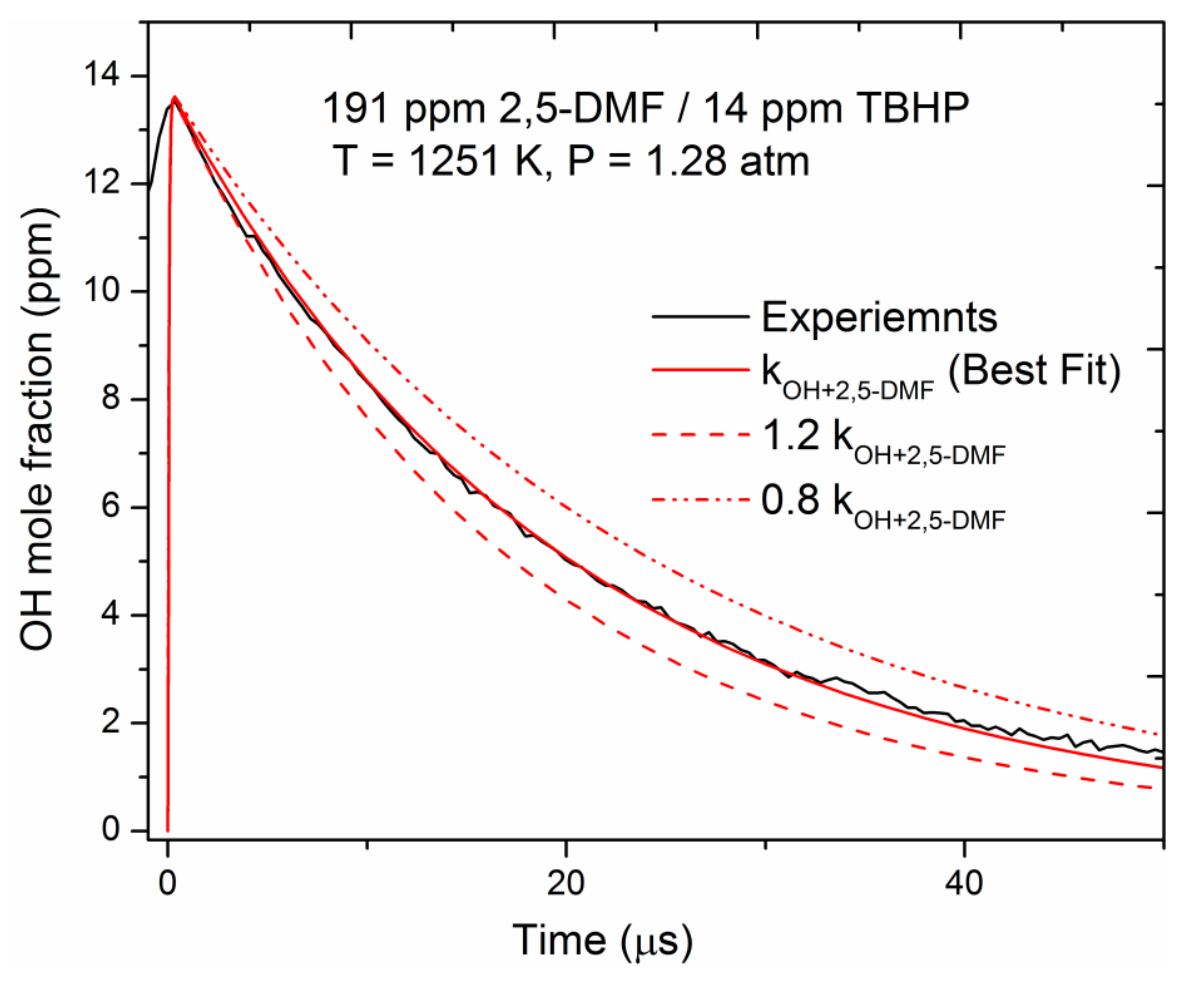

409 Figure 10. A representative measured $\mathrm{OH}$ mole fraction profile for measuring the rate coefficient 410 of 2,5 DMF $+\mathrm{OH}$ at $1251 \mathrm{~K}$ and $1.28 \mathrm{~atm}$. Best-fit simulated rate coefficient and perturbations of $411 \pm 20 \%$ are also shown. Simulations are performed using the Togbé et al.[22] mechanism.

412 


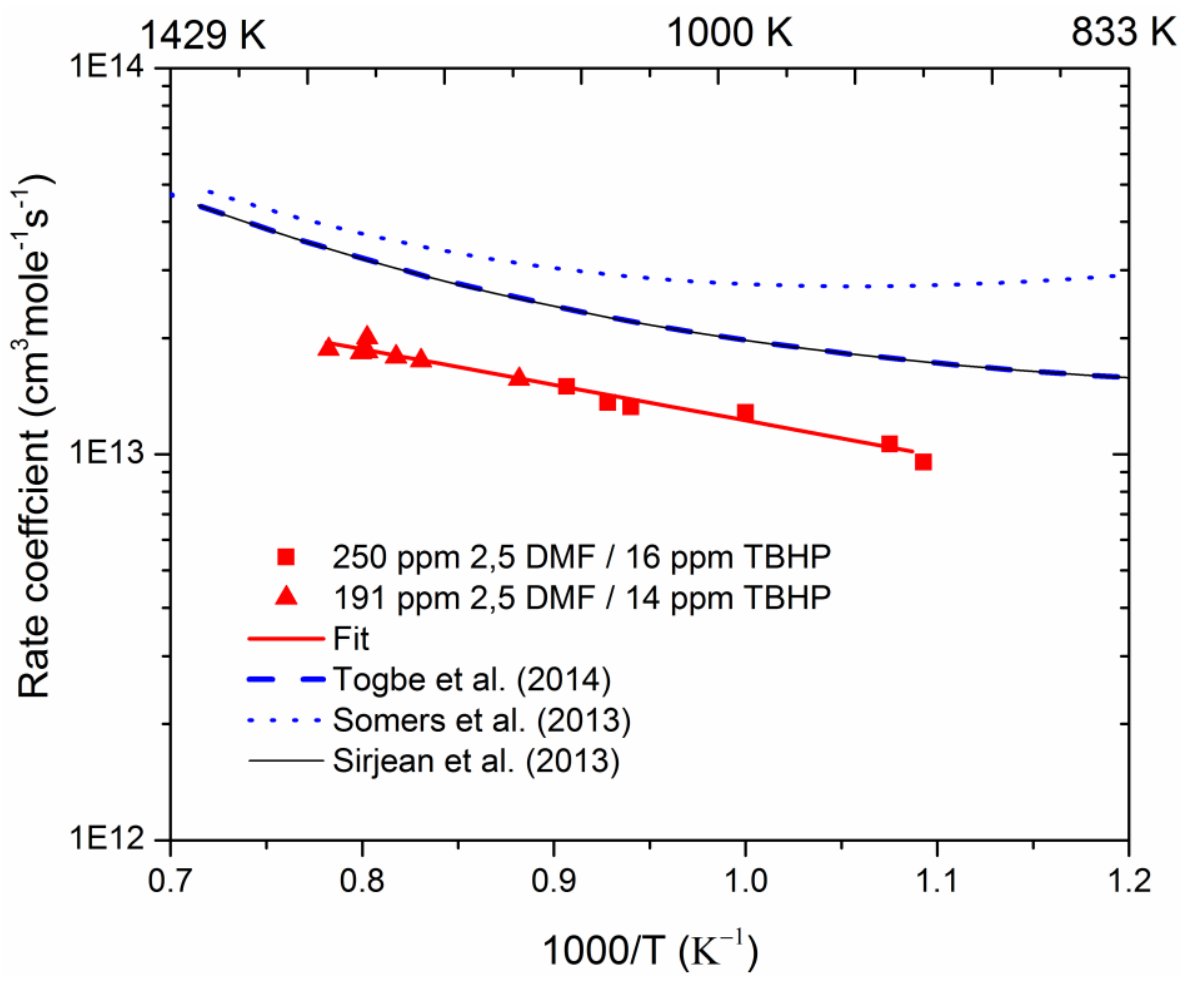

Figure 11. Arrhenius plot for 2,5 DMF $+\mathrm{OH}\left(k_{3}\right)$. Rate coefficients adopted in the mechanisms of 416 Togbé et al.[22], Sirjean et al.[16] and Somers et al.[17] are also shown. 


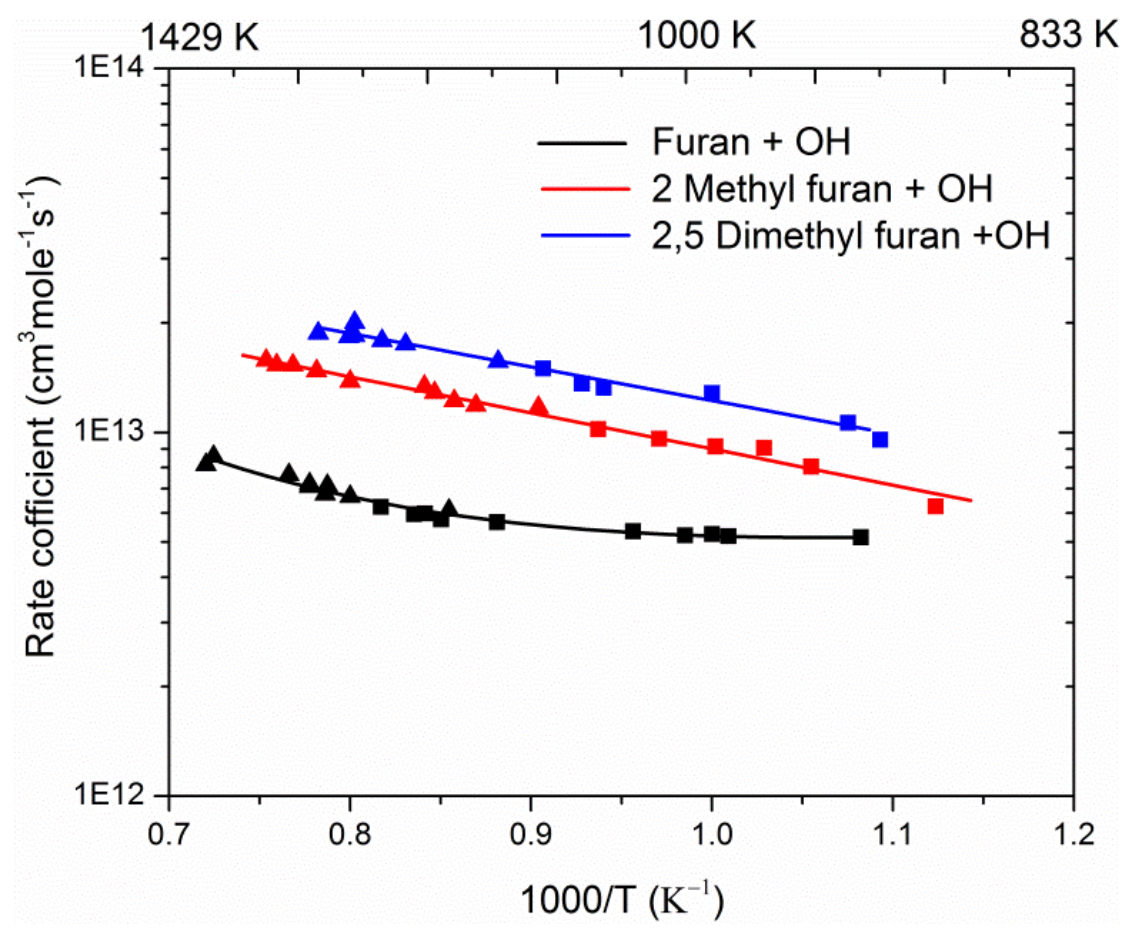

419 Figure 12. Comparison of the overall rate coefficients.

420

421 


\section{Supplementary Material}

423

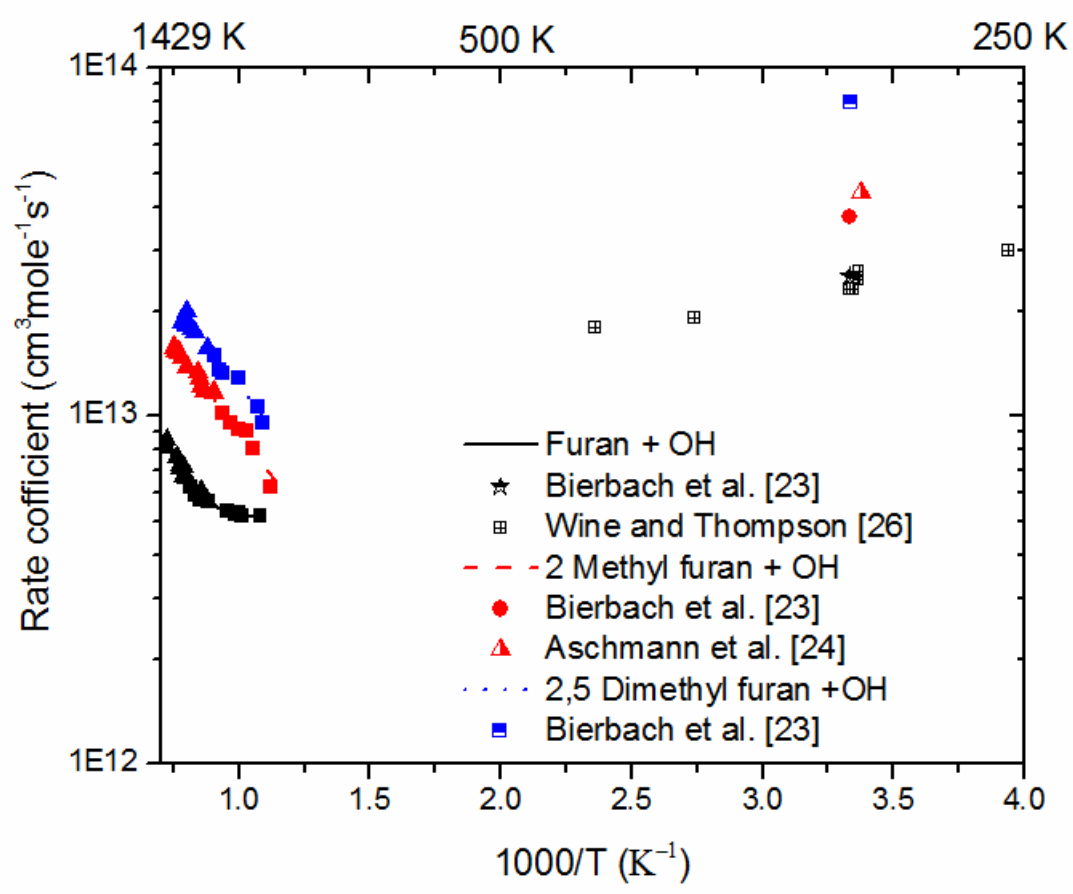

424

425

Figure S1: Comparison of current high-temperature measurements with low-

426 temperature literature data

427

428 
430

431

432

433

434

435

436

437

438

439

440

441

442

443

444

445

446

447

448

449

450

451

452

453

454

455

456

457

458

459

460

461

462

463

464

465

466

467

468

469

470

471

472

473

[1] F. Cherubini, A.H. Strømman, Chemicals from lignocellulosic biomass: opportunities, perspectives, and potential of biorefinery systems, Biofuels, Bioproducts and Biorefining, 5 (2011) 548-561.

[2] Y. Román-Leshkov, C.J. Barrett, Z.Y. Liu, J.A. Dumesic, Production of dimethylfuran for liquid fuels from biomass-derived carbohydrates, Nature, 447 (2007) 982-985.

[3] W. Yang, A. Sen, One-Step Catalytic Transformation of Carbohydrates and Cellulosic Biomass to 2, 5Dimethyltetrahydrofuran for Liquid Fuels, ChemSusChem, 3 (2010) 597-603.

[4] L.S. Tran, B. Sirjean, P.-A. Glaude, R. Fournet, F. Battin-Leclerc, Progress in detailed kinetic modeling of the combustion of oxygenated components of biofuels, Energy, 43 (2012) 4-18.

[5] P.P. Organ, J.C. Mackie, Kinetics of pyrolysis of furan, J. Chem. Soc., Faraday Trans., 87 (1991) 815823.

[6] S. Zhong, R. Daniel, H. Xu, J. Zhang, D. Turner, M.L. Wyszynski, P. Richards, Combustion and emissions of 2, 5-dimethylfuran in a direct-injection spark-ignition engine, Energy \& Fuels, 24 (2010) 2891-2899.

[7] R. Daniel, G. Tian, H. Xu, M.L. Wyszynski, X. Wu, Z. Huang, Effect of spark timing and load on a DISI engine fuelled with 2, 5-dimethylfuran, Fuel, 90 (2011) 449-458.

[8] R. Daniel, L. Wei, H. Xu, C. Wang, M.L. Wyszynski, S. Shuai, Speciation of hydrocarbon and carbonyl emissions of 2, 5-dimethylfuran combustion in a DISI engine, Energy \& Fuels, 26 (2012) 6661-6668.

[9] D.A. Rothamer, J.H. Jennings, Study of the knocking propensity of 2, 5-dimethylfuran-gasoline and ethanol-gasoline blends, Fuel, 98 (2012) 203-212.

[10] M. Thewes, M. Muether, S. Pischinger, M. Budde, A. Brunn, A. Sehr, P. Adomeit, J. Klankermayer, Analysis of the impact of 2-methylfuran on mixture formation and combustion in a direct-injection spark-ignition engine, Energy \& Fuels, 25 (2011) 5549-5561.

[11] M. Grela, V. Amorebieta, A. Colussi, Very low pressure pyrolysis of furan, 2-methylfuran and 2, 5dimethylfuran. The stability of the furan ring, The Journal of Physical Chemistry, 89 (1985) 38-41.

[12] L. Wei, C. Tang, X. Man, X. Jiang, Z. Huang, High-temperature ignition delay times and kinetic study of furan, Energy \& Fuels, 26 (2012) 2075-2081.

[13] Z. Tian, T. Yuan, R. Fournet, P.-A. Glaude, B. Sirjean, F. Battin-Leclerc, K. Zhang, F. Qi, An experimental and kinetic investigation of premixed furan/oxygen/argon flames, Combustion and flame, 158 (2011) 756-773.

[14] K.P. Somers, J.M. Simmie, F. Gillespie, U. Burke, J. Connolly, W.K. Metcalfe, F. Battin-Leclerc, P. Dirrenberger, O. Herbinet, P.-A. Glaude, A high temperature and atmospheric pressure experimental and detailed chemical kinetic modelling study of 2-methyl furan oxidation, Proceedings of the Combustion Institute, 34 (2013) 225-232.

[15] L. Wei, C. Tang, X. Man, Z. Huang, Shock-Tube Experiments and Kinetic Modeling of 2-Methylfuran Ignition at Elevated Pressure, Energy \& Fuels, 27 (2013) 7809-7816.

[16] B. Sirjean, R. Fournet, P.-A. Glaude, F. Battin-Leclerc, W. Wang, M.A. Oehlschlaeger, Shock tube and chemical kinetic modeling study of the oxidation of 2, 5-dimethylfuran, The Journal of Physical Chemistry A, 117 (2013) 1371-1392.

[17] K.P. Somers, J.M. Simmie, F. Gillespie, C. Conroy, G. Black, W.K. Metcalfe, F. Battin-Leclerc, P. Dirrenberger, O. Herbinet, P.-A. Glaude, A comprehensive experimental and detailed chemical kinetic modelling study of 2, 5-dimethylfuran pyrolysis and oxidation, Combustion and flame, 160 (2013) 22912318.

[18] K.P. Somers, J.M. Simmie, W.K. Metcalfe, H.J. Curran, The pyrolysis of 2-methylfuran: a quantum chemical, statistical rate theory and kinetic modelling study, Phys. Chem. Chem. Phys., 16 (2014) 53495367. 
474

[19] M.A. Eldeeb, B. Akih-Kumgeh, Reactivity trends in furan and alkyl furan combustion, Energy \& Fuels, 28 (2014) 6618-6626.

[20] D. Liu, C. Togbé, L.-S. Tran, D. Felsmann, P. Oßwald, P. Nau, J. Koppmann, A. Lackner, P.-A. Glaude, B. Sirjean, Combustion chemistry and flame structure of furan group biofuels using molecular-beam mass spectrometry and gas chromatography-Part I: Furan, Combustion and flame, 161 (2014) 748-765. [21] L.-S. Tran, C. Togbé, D. Liu, D. Felsmann, P. Oßwald, P.-A. Glaude, R. Fournet, B. Sirjean, F. BattinLeclerc, K. Kohse-Höinghaus, Combustion chemistry and flame structure of furan group biofuels using molecular-beam mass spectrometry and gas chromatography-Part II: 2-Methylfuran, Combustion and flame, 161 (2014) 766-779.

[22] C. Togbé, L.-S. Tran, D. Liu, D. Felsmann, P. Oßwald, P.-A. Glaude, B. Sirjean, R. Fournet, F. BattinLeclerc, K. Kohse-Höinghaus, Combustion chemistry and flame structure of furan group biofuels using molecular-beam mass spectrometry and gas chromatography-Part III: 2, 5-Dimethylfuran, Combustion and flame, 161 (2014) 780-797.

[23] A. Bierbach, I. Barnes, K. Becker, Rate coefficients for the gas-phase reactions of hydroxyl radicals with furan, 2-methylfuran, 2-ethylfuran and 2, 5-dimethylfuran at 300 $\pm 2 \mathrm{~K}$, Atmospheric Environment. Part A. General Topics, 26 (1992) 813-817.

[24] S.M. Aschmann, N. Nishino, J. Arey, R. Atkinson, Kinetics of the Reactions of OH Radicals with 2-and 3-Methylfuran, 2, 3-and 2, 5-Dimethylfuran, and E-and Z-3-Hexene-2, 5-dione, and Products of $\mathrm{OH}+2$, 5Dimethylfuran, Environ. Sci. Technol., 45 (2011) 1859-1865.

[25] S.M. Aschmann, N. Nishino, J. Arey, R. Atkinson, Products of the OH Radical-Initiated Reactions of Furan, 2-and 3-Methylfuran, and 2, 3-and 2, 5-Dimethylfuran in the Presence of NO, The Journal of Physical Chemistry A, 118 (2013) 457-466.

[26] P. Wine, R. Thompson, Kinetics of $\mathrm{OH}$ reactions with furan, thiophene, and tetrahydrothiophene, International journal of chemical kinetics, 16 (1984) 867-878.

[27] E. Gómez Alvarez, E. Borrás, J. Viidanoja, J. Hjorth, Unsaturated dicarbonyl products from the $\mathrm{OH}-$ initiated photo-oxidation of furan, 2-methylfuran and 3-methylfuran, Atmos. Environ., 43 (2009) 16031612.

[28] S.H. Mousavipour, S. Ramazani, Z. Shahkolahi, Multichannel RRKM-TST and Direct-Dynamics VTST Study of the Reaction of Hydroxyl Radical with Furan, The Journal of Physical Chemistry A, 113 (2009) 2838-2846.

[29] J.M. Anglada Rull, The Gas Phase HO-Initiated Oxidation of Furan: A Theoretical Investigation on the Reaction Mechanism, Open Chemical Physics Journal, 1 (2008) 80-93.

[30] W. Zhang, B. Du, L. Mu, C. Feng, Computational study on the mechanism for the reaction of OH with 2-methylfuran, Journal of Molecular Structure: THEOCHEM, 851 (2008) 353-357.

[31] W. Zhang, B. Du, L. Mu, C. Feng, Mechanism for the gas-phase reaction between $\mathrm{OH}$ and 3methylfuran: A theoretical study, International Journal of Quantum Chemistry, 108 (2008) 1232-1238.

[32] D.A. Hansen, R. Atkinson, J.N. Pitts, Rate constants for the reaction of hydroxyl radicals with a series of aromatic hydrocarbons, The Journal of Physical Chemistry, 79 (1975) 1763-1766.

[33] R. Kee, F. Rupley, J. Miller, The Chemical Thermodynamic Data Base, Report No, SAND87-8215B. UC-4, Sandia National Laboratory, (1987).

[34] R.S. Chrystie, E.F. Nasir, A. Farooq, Towards simultaneous calibration-free and ultra-fast sensing of temperature and species in the intrapulse mode, Proceedings of the Combustion Institute, 35 (2015) 3757-3764.

[35] J. Badra, A.E. Elwardany, F. Khaled, S.S. Vasu, A. Farooq, A shock tube and laser absorption study of ignition delay times and $\mathrm{OH}$ reaction rates of ketones: 2-Butanone and 3-buten-2-one, Combustion and Flame, 161 (2014) 725-734.

[36] A. Elwardany, E. Nasir, E. Es-sebbar, A. Farooq, Unimolecular decomposition of formic and acetic acids: A shock tube/laser absorption study, Proceedings of the Combustion Institute, (2014). 
[37] V. Vasudevan, D.F. Davidson, R.K. Hanson, High-temperature measurements of the reactions of $\mathrm{OH}$ with toluene and acetone, The Journal of Physical Chemistry A, 109 (2005) 3352-3359.

[38] T. Seta, M. Nakajima, A. Miyoshi, High-temperature reactions of $\mathrm{OH}$ radicals with benzene and toluene, The Journal of Physical Chemistry A, 110 (2006) 5081-5090.

[39] J.T. Herbon, Shock tube measurements of $\mathrm{CH} 3+\mathrm{O} 2$ kinetics and the heat of formation of the $\mathrm{OH}$ radical, in, Stanford University, 2004.

[40] K.-Y. Lam, D.F. Davidson, R.K. Hanson, High-Temperature Measurements of the Reactions of OH with a Series of Ketones: Acetone, 2-Butanone, 3-Pentanone, and 2-Pentanone, The Journal of Physical Chemistry A, 116 (2012) 5549-5559.

[41] J. Badra, A.E. Elwardany, F. Khaled, S.S. Vasu, A. Farooq, A shock tube and laser absorption study of ignition delay times and $\mathrm{OH}$ reaction rates of ketones: 2-Butanone and 3-buten-2-one, Combust. Flame, (2013).

[42] S.S. Vasu, J. Zádor, D.F. Davidson, R.K. Hanson, D.M. Golden, J.A. Miller, High-Temperature Measurements and a Theoretical Study of the Reaction of $\mathrm{OH}$ with 1, 3-butadiene, The Journal of Physical Chemistry A, 114 (2010) 8312-8318.

[43] S.S. Vasu, Z. Hong, D.F. Davidson, R.K. Hanson, D.M. Golden, Shock tube/laser absorption measurements of the reaction rates of $\mathrm{OH}$ with ethylene and propene, J. Phys. Chem. A, 114 (2010) 11529-11537.

[44] S.W. Benson, H.E. O'Neal, Kinetic data on gas phase unimolecular reactions, in, DTIC Document, 1970.

[45] R. Kee, F. Rupley, J. Miller, M. Coltrin, J. Grcar, E. Meeks, H. Moffat, A. Lutz, G. Dixon-Lewis, M. Smooke, CHEMKIN-PRO, Release 15105, in, Reaction Design, Inc.: San Diego, CA, 2010.

[46] G.A. Pang, R.K. Hanson, D.M. Golden, C.T. Bowman, High-Temperature Measurements of the Rate Constants for Reactions of $\mathrm{OH}$ with a Series of Large Normal Alkanes: n-Pentane, n-Heptane, and nNonane, Z. Phys. Chem., 225 (2011) 1157-1178.

[47] M.A. Oehlschlaeger, D.F. Davidson, R.K. Hanson, High-temperature ethane and propane decomposition, Proc. Combust. Inst., 30 (2005) 1119-1127.

[48] N. Srinivasan, M.-C. Su, J. Michael, High-Temperature Rate Constants for $\mathrm{CH} 3 \mathrm{OH}+\mathrm{Kr} \rightarrow$ Products, $\mathrm{OH}+\mathrm{CH} 3 \mathrm{OH} \rightarrow$ Products, $\mathrm{OH}+(\mathrm{CH} 3) 2 \mathrm{CO} \rightarrow \mathrm{CH} 2 \mathrm{COCH} 3+\mathrm{H} 2 \mathrm{O}$, and $\mathrm{OH}+\mathrm{CH} 3 \rightarrow \mathrm{CH} 2+\mathrm{H} 2 \mathrm{O}$, The Journal of Physical Chemistry A, 111 (2007) 3951-3958. 